\title{
Prohibitin-Targeting Peptide 1
}

National Cancer Institute

\section{Source}

National Cancer Institute. Prohibitin-Targeting Peptide 1. NCI Thesaurus. Code C95709.

A chimeric, 25-mer peptide that targ ets prohibitin, with potential antineoplastic activity. Prohibitin-targeting peptide 1 (prohibitin-TP01) consists of a fat-targeting motif (CKGGRAKDC), two repeats of a proapoptotic peptide motif (KLAKLAK) and a GG linker. This peptide binds specifically to prohibitin in the white adipose vasculature; upon receptor-mediated cell internalization, the ligand/receptor complex triggers apoptosis and results in ablation of white fat. Destruction of white fat may potentially have positive consequences for men with prostate cancer since a high level of white fat has been implicated as a critical contributing factor in poor prostate cancer outcome. Prohibitin, a multifunctional membrane-associated protein that is thought to regulate cell survival and growth, has been shown by immunohistochemical analysis to be expressed in the membrane of endothelial cells in white adipose tissue. 